
segurança ontológica de expatriados brasileiros. Consumer Behavior Review, 5(3), 321-338.

ISSN: 2526-7884

Editor: Prof. Dr. Marconi Freitas da Costa

E-mail: cbr@ufpe.br
Avaliação: Double blind review

Recebido: 18 de dezembro de 2020

Aprovado: 2 de junho de 2021

\title{
MINHAS CASAS E MINHAS ESCOLHAS: ARTICULAÇÕES ENTRE CONSUMO E SEGURANÇA ONTOLÓGICA DE EXPATRIADOS BRASILEIROS
}

\author{
My Homes and My Choices: Links between consumption and ontological security of brazilian
}

expatriates

\author{
Ana Luisa Menna Barreto Amil ${ }^{1}$ \\ ORCID: http://orcid.org/0000-0002-9585-0475 \\ E-mail: anabarretoamil@gmail.com \\ João Felipe Rammelt Sauerbronn ${ }^{1}$ \\ ORCID: http://orcid.org/0000-0001-6453-9425 \\ E-mail: joao.sauerbronn@gmail.com \\ ${ }^{1}$ Universidade Unigranrio, Rio de Janeiro, Brasil
}

\begin{abstract}
Resumo
A desmobilização de espaço e lugar, vivenciada por expatriados - pessoas pertencentes a organizações internacionais ou expatriados autoiniciados, traz no pacote um impacto de contrastes, tanto cultural quanto social. 0 objetivo desta pesquisa é investigar como o consumo colabora no ajustamento das identidades do expatriado e que aspectos de segurança ontológica foram revelados nas experiências vivenciadas. A base teórica da pesquisa é apoiada na teoria apontada por
\end{abstract}

\begin{abstract}
The demobilization of space and place, experienced by expatriates - people belonging to international organizations or self-initiated expatriates, brings in the package an impact of contrasts, both cultural and social. The aim of this research is to investigate how consumption contributes to the adjustment of expatriate identities and what aspects of ontological security were revealed in the experiences. The theoretical basis of the research is supported by the theory pointed
\end{abstract}


Giddens (1991), na qual todas as pessoas buscam um referencial de segurança ontológica de alguma espécie, baseada na manutenção da sua narrativa biográfica, em aspectos relacionados a familiaridade de lugares, em relações de confiança, nas escolhas de consumo, em crenças que minimizem a ansiedade, em tradições e rotinas cotidianas. A abordagem de pesquisa é qualitativa, de cunho exploratório. 0 consumo, nesse contexto, não só trouxe um lugar de distinção como favoreceu a construção de relações significativas, revelando um sujeito que faz suas escolhas de consumo, alinhado ao seu novo projeto de vida em outro país como expatriado, apoiado em atributos que constituem a sua identidade, escolhas de consumo que carregam sentido, trazem confiança e minimizam as carências sentidas em outro país.

Palavras-chave: Expatriado; identidade; nível de confiança; Consumo; Segurança ontológica. out by Giddens (1991), in which all people seek a referential of ontological security of some kind, based on the maintenance of their biographical narrative, in aspects related to the familiarity of places, in relationships of confidence, in consumption choices, in beliefs that minimize anxiety, in traditions and daily routines. The research approach is qualitative and exploratory. Consumption, in this context, not only brought a place of relaxation but favored the construction of meaningful relationships, revealing a subject who makes his consumption choices, aligned with his new life project in another country as an expatriate, supported by attributes that constitute their identity, consumption choices that carry meaning, bring confidence and minimize the needs felt in another country.

Keywords: Expatriate; Identity; Level of trust; Consumption; Ontological security.

This work is licensed under a Creative Commons Attribution 4.0 International License.

\section{INTRODUÇÃO}

O ambiente globalizado, com amplo e rápido acesso a informações, a internacionalização de organizações e o intenso fluxo de pessoas por todo o mundo geram a necessidade de entender a mobilidade internacional demandada por expatriados. Giddens (1991) define a globalização como o avivamento das relações sociais em escala mundial e o mercado de trabalho está inserido nesse cenário, repercutindo em novas formas de viver e em novas experiências de expatriação. 0 expatriado é uma pessoa que se retira de maneira voluntária ou por obrigação de sua própria pátria (Ferreira, 1993). Profissionais brasileiros em muitos momentos têm de deixar o país, onde vivem de forma consolidada, para se encaixarem em novos ambientes, iniciando uma nova história, tendo que estar preparados para construir não só novas relações, como também espaços onde se sintam estáveis.

Levantamentos realizados pela Fundação Alexandre de Gusmão, vinculada ao Ministério das Relações Exteriores do Brasil, para a V Conferência "Brasileiros no Mundo", dão conta de que 3.083.216 brasileiros vivem fora do Brasil (Ministério das Relações Exteriores, 2016). Dentre vários motivos para emigração apontados na conferência, a principal justificativa para os brasileiros deixarem o país está relacionada a aspectos econômicos, ainda que na decisão de partir sejam considerados, de forma consciente ou não, outros fatores de ordem cultural ou mesmo psicológica. A nova inserção social desses emigrantes varia segundo a escolha do país e nessa escolha já estão geralmente incorporados muitos condicionamentos do novo modo de vida.

A complexidade inerente à mobilidade transnacional traz para discussão a questão do reencaixe levantado por Giddens (2002), não somente relacionado aos lugares, mas também às novas rotinas e relações sociais, muitas vezes dificultadas pelas diferenças culturais e pelo desconforto frente a o que não é familiar. O lugar atua como palco das narrativas, como espaço de práticas sociais que nos caracterizam e com as quais nossas identidades estão ligadas. Nele, estabelecemos vínculos e vivemos experiências que contribuem para as nossas narrativas identitárias. Lugares contribuem, de alguma forma, para a nossa segurança ontológica (Giddens, 2002), por já serem familiares. Construímos identidades ligadas a lugares, escolhemos relacionamentos e criamos hábitos que nos caracterizam e nos fazem sentir bem. 
No momento anterior à expatriação, planos são traçados baseados na crença pessoal de cada expatriado, revela-se onde a sua confiança está depositada, características presentes quando a decisão é tomada antes de iniciar uma experiência em outro país. Para continuar se sentido bem ou, usando o conceito de Giddens (1991), para proteger sua segurança ontológica, o expatriado buscará todos esses atributos, visando construir uma nova narrativa que atenda ao seu projeto de vida. Para Giddens (1991), a segurança ontológica tem relação com "ser" ou, nos termos da fenomenologia, com o "ser-nomundo". Refere-se a um fenômeno emocional ao invés de cognitivo, e está arraigado no inconsciente do ser humano. 0 expatriado busca atributos que facilitem sua adaptação e que contribuam para a sua segurança ontológica quando estabelecer suas relações sociais e escolhas de consumo e de um modo de vida que lhe traga confiança e familiaridade dentro do novo contexto.

Dessa forma, o expatriado busca meios de se adequar a um novo lugar, a novas pessoas e coisas para se sentir no controle do plano da sua vida. 0 consumo pode ter um papel de facilitador, na medida em que resgata valores, revela significados pessoais e permite reviver experiências que colaboram para a sua segurança ontológica. Para Canclini (1999), a escolha dos bens é uma forma de demonstrar publicamente o que é valioso para o consumidor, comunicando um sentido social. Diversos estudos já trataram das relações entre consumo, identidade e representação do sujeito tanto de formas mais amplas (vide: Campbell, 2006; Rocha, 2006; Thompson \& Loveland, 2015), quanto em contextos específicas (vide: Schau, Gilly, \& Wolfinbarger, 2009; Cupolillo \& Ayrosa, 2016; Carvalho, Luna, Goldsmith, 2019; Borges, Campos, Cappelle \& Rezende, 2020). Gouveia e Ayrosa (2020) estudaram a produção do self ontologicamente seguro a partir a interação das narrativas e práticas relacionadas ao corpo e o consumo, mas ainda preciso avançarmos no caminho de entender as relações entre identidade, consumo e segurança ontológica. Giddens (2002, p. 160) diz que as "pessoas, através do consumo, buscam produzir a aparência de um eu socialmente valorizado".

A identidade com seu caráter múltiplo, mutável e relacional é adaptada conforme a interação social e construída a partir da narrativa reflexiva do sujeito. Segundo Giddens (2002, p. 79), as "pessoas buscam a auto realização caracterizada no estilo de vida escolhido e traduzido num conjunto de práticas que atendem às suas necessidades utilitárias". 0 estilo de vida determina uma narrativa particular, definida por um conjunto de hábitos e orientações que produzem uma percepção de continuidade da segurança ontológica. Dessa forma, o presente trabalho tem como objetivo investigar como o consumo colabora no ajustamento das identidades do expatriado e que aspectos de segurança ontológica foram revelados nas experiências vivenciadas por eles. Para atingir esse objetivo utilizamos o suporte teórico da segurança ontológica, conforme proposto por Giddens (1991), para analisar as entrevistas coletadas junto a nove brasileiros expatriados moradores de quatro países distintos. Os resultados mostram como o consumo é utilizado por expatriados como forma de sentirem-se ontologicamente seguros.

\section{FUNDAMENTAÇÃO TEÓRICA}

Nesta seção apresentamos o suporte teórico utilizado no trabalho. Assim, em primeiro lugar discutimos o conceito de expatriado e apontamos suas conexões iniciais com identidade, consumo e segurança ontológica. Em seguida, trazemos a discussão mais profunda a respeito de consumo e identidade e abordamos as formas de conectar as atividades de consumo à satisfação de necessidades de construções identitárias de forma dinâmica e constante. Por fim, apresentamos o conceito de segurança ontológica, reforçamos suas possíveis relações com o consumo e apresentamos as categorias analíticas retiradas desse referencial teórico e usadas posteriormente na análise dos dados.

\section{Definindo o Expatriado}

Oportuno trazer um esclarecimento quanto à natureza de ser um imigrante ou um expatriado. Adams e Van de Vijver (2015) dizem que o imigrante tem a característica de mudar de país por força de circunstâncias externas, como motivos políticos, guerras e outras tensões não provocadas pelo próprio, enquanto o expatriado realiza a experiência de migração por vontade própria, normalmente motivado por sua escolha ou seus planos de vida, demanda do trabalho, busca de aprimoramento profissional, ou por uma melhor qualidade de vida. 
Nos tempos em que vivemos, chamado por Giddens (2002) de Modernidade, passamos por adaptações no modo de viver, em que somos afetados de várias formas. 0 mesmo se verifica na vida de expatriados, na adaptação de vida e nos valores pessoais visitados nas suas decisões, como a confiança em sistemas abstratos, como pré-requisito para lidar com o distanciamento tempo-espaço. Para Giddens (2002, p.9) "a reorganização do tempo e do espaço, somada aos mecanismos de desencaixe, radicaliza e globaliza traços institucionais preestabelecidos da modernidade; e atua na transformação do conteúdo e da natureza da vida social cotidiana". A relação com os alimentos que comemos, os imóveis que habitamos, as formas de transporte que usamos e outros fenômenos de consumo serão sentidas no novo modo de vida, interferindo assim nas escolhas feitas pelos expatriados (Usunier, 1999; Hu \& Duval, 2008; Bundy, 2017).

No estudo com expatriados, Adams e Van de Vijver (2015) perceberam que os mesmos possuem mais liberdade para ajustar e negociar suas identidades, pelo motivo de suas condições de migrantes serem temporárias. Assim, para gerirem de forma satisfatória suas identidades, os expatriados precisam encontrar meios de lidar com as incertezas associadas ao novo ambiente, o que nos remete à segurança ontológica apontada por Giddens e tratada mais à frente neste trabalho. Adams e Van de Vijver (2015) apontam ainda que nesta interação de culturas vivenciadas pelos expatriados ocorrem ajustes que podem ocorrer a nível psicológico, traduzido em bem-estar, tanto subjetivo como sociocultural de natureza comportamental, que revelam o quanto o sujeito está experimentando de conforto, imerso nesse novo contexto cultural. A identidade pessoal engloba os aspectos intrapessoais como valores, crenças, metas do sujeito, que são importantes para se definir como único e distinto (Adams \& Van de Vijver, 2015). Nesta dimensão, a identidade do expatriado engloba suas preferências, seus hábitos e suas habilidades, sendo esta experiência como expatriado uma oportunidade para ser testado nesses vários aspectos, definindo assim, um padrão de adaptação. $\mathrm{Na}$ próxima seção exploramos mais profundamente as relações entre consumo e identidade e os desdobramentos no caso dos expatriados.

\section{Consumo e Identidade}

Identidades são mediadas e reconfiguradas para atenderem a uma demanda de segurança ontológica e maior confiança, as identidades são produzidas para atender a vários contextos sociais, com o fim de estabelecer relações de confiança, se adaptar aos riscos relacionados a novos ambientes, elaborar novas rotinas relacionadas a maior confiança nos planos futuros. De acordo com Giddens (2002), as inseguranças presentes no indivíduo impactam na sua identidade e no sentimento de continuidade biográfica; e o consumo se revela como um fator que colabora para manutenção da sua biografia, quando ele faz suas escolhas de consumo. As identidades construídas se relacionam nos ambientes social e cultural, de acordo com o plano definido pelo sujeito. 0 consumo se relaciona como um instrumento disponível a estas identidades, para colaborar nas suas construções, aliviar as tensões e comunicar significado.

Segundo Hall (2006), o sujeito pós-moderno não apresenta mais identidade fixa, essencial ou permanente, mas transformada continuamente nas suas interações nos sistemas culturais e sociais em que participa: uma identidade definida factualmente e não mais herdada naturalmente. Giddens (2002) nos faz entender que quanto maior a instabilidade da identidade no mundo pós tradicional, maior deve ser o envolvimento no que ele chama de projeto reflexivo do eu. Um projeto reflexivo que envolve autoexames, autofiscalização, planejamento ininterrupto em todos os componentes da vida, a fim de combiná-los com vistas a uma narrativa coerente, chamada "o eu".

0 "eu" é compreendido reflexivamente pela pessoa em termos de sua biografia, de sua capacidade de manter em andamento uma narrativa particular na busca de um sentido à sensação de continuidade biográfica capaz de captar reflexivamente e, em maior ou menor medida, comunicar a outras pessoas (Giddens, 2002). A autoidentidade é, então, forjada na interação com o mundo externo. Os estilos de vida escolhidos contribuem para compor a identidade do indivíduo, nesse processo as escolhas de consumo participam ativamente, conforme o seu plano de vida é processado e escolhas são realizadas. 
As nossas identidades são comunicadas na nossa vida diária que pode ser entendida como um desenrolar de rotinas que desembocam em práticas habituais como as relações pessoais, o trabalho e o consumo. Essas atividades são capazes de divulgar nossas intenções subjetivas e comunicar valores que vão além do aspecto econômico, revelando também aspectos emocionais presentes nas nossas escolhas de consumo, objeto do presente trabalho. Ao fazermos nossas escolhas de consumo, colaboramos com a construção das identidades e das relações sociais (Slater, 2001). Os objetos de consumo sempre foram utilizados para reproduzir, culturalmente, identidades sociais. A cultura do consumo, segundo Slater (2001), nos revela um acordo social, no qual as partes envolvidas são a cultura vivida, os recursos sociais e materiais simbólicos e os modos de vidas significativos. Essas dimensões também são mediadas pelo mercado e ao ocorrerem mudanças no consumo há mudanças também nas identidades.

Segundo Barbosa (2004), consumir e utilizar elementos da cultura material para construir e afirmar identidades é uma prática universal. 0 consumo contribui para a reconstrução de uma realidade social, na medida em que o consumidor pode agir ativamente no cenário, fazendo suas escolhas. Por meio das atividades de consumo, o sujeito se expressa e colabora na legitimação da sua identidade (Belk, 1988). A cultura é um processo dinâmico na geração de hábitos de consumo que comunicam, fazem sentido, dão segurança à novas formas de vida e colaboram para o fortalecimento das identidades. Através do consumo do consumo indivíduos e objetos adquirem sentido, produzem significações e distinções sociais (Rocha, 1995). Para Canclini (1999), a escolha dos bens é uma forma de demonstrar publicamente o que é valioso para si, comunicando um sentido social.

O consumo contemporâneo, segundo Slater (2001), trata de como as necessidades humanas se relacionam com as coisas que o mundo disponibiliza. Essas necessidades podem ser satisfeitas através da busca de significados ou em experiências materiais. Nesse sentido, todo consumo é cultural, porque envolve significados e traduz um modo de vida escolhido. Nesse contexto, a cultura de consumo define um acordo social no qual interagem recursos sociais e materiais simbólicos são traduzidos em modos de vida significativos (Slater, 2011). Essa interação é mediada pelo mercado em contextos sociais específicos.

Em pesquisa realizada com expatriados por Thompson e Tambiah (1999), foram investigadas práticas de consumo que revelam tentativas de amenizar as suas inseguranças. Adams e Van de Vijver (2015) apontam que o caráter ajustável da identidade é um facilitador no ajustamento psicossocial e do bem-estar do sujeito expatriado. Os autores também argumentam que pode ocorrer um outro tipo de ajuste, chamado superficial, no qual o sujeito absorve menos e mantém suas características, sendo o contexto em que está inserido encarado como um colaborador, neste quesito.

O consumo oferece acesso a significados e identidades que os indivíduos buscam e é também através dessa atividade que os indivíduos constroem seus "eu" e procuram pela segurança ontológica. 0 consumidor seria alguém engajado em um projeto cultural cujo propósito é completar o self a partir de um sistema que supre as pessoas com os materiais culturais necessários à realização de suas variadas concepções do que é ser um homem ou uma mulher, um cidadão ou um profissional (McCracken, 2003). Os indivíduos buscam produzir a aparência de um "eu" socialmente valorizado através do consumo, o qual funciona como um produtor de sentidos e identidades, caracterizando, assim, as escolhas de estilos de vida. Esse entendimento se alinha aos aspectos de segurança ontológica trazidos por Giddens (2002) e apresentados na próxima seção.

\section{Segurança Ontológica}

Segundo Giddens (2002, p.47) todos os indivíduos desenvolvem um referencial de segurança ontológica de alguma espécie, baseado em vários tipos de rotinas. Para o autor, "ser ontologicamente seguro é ter, no nível do inconsciente e da consciência prática, respostas para questões existenciais fundamentais que toda vida humana, de certa maneira, coloca".

Giddens (2002) entende que a ansiedade, confiança e as rotinas cotidianas estão, de tal modo, relacionadas entre si, e que podemos considerar as práticas da vida diária como um mecanismo de enfrentamento. Para o autor, o indivíduo, através de um projeto reflexivo do "eu", contribui mantendo suas narrativas biográficas coerentes e continuamente revisadas. 
Na vida social moderna, a noção de estilo de vida assume um significado particular. Quanto mais a tradição perde seu domínio, e quanto mais a vida diária é reconstituída em termos do jogo dialético entre o local e o global, tanto mais os indivíduos são forçados a escolher um estilo de vida a partir de uma diversidade de opções. (GIDDENS, 2002, p.12 e 13).

De acordo com Giddens (2002), na pluralidade de ambientes promovida pela vida social moderna, de diversificações no mundo privado e no público, as pessoas poderão se sentir desconfortáveis, sendo motivadas ou não a se aprofundarem nesses ambientes, direcionadas pelas escolhas de estilos de vida. Segundo o autor, a reflexividade e o seu caráter de observação contínua do fluxo da vida social permitem ao sujeito um posicionamento, relacionado diretamente com a continuidade das práticas, traduzido na incorporação rotineira de conhecimentos ou informações novas em situações, as quais serão reconstituídas ou reorganizadas (GIDDENS, 2009).

Giddens (2002) trata também das inquietações vivenciadas pelo ser humano e que muitas vezes podem ser satisfeitas através do seu projeto biográfico, da constituição de identidades; trazendo a responsabilidade e o compromisso de repensar o plano de vida. A confiança, a segurança ontológica e o sentimento de continuidade das coisas e pessoas permanecem ligados entre si, na personalidade adulta, de acordo com Giddens (2002). O autor cita a confiança pessoal como um projeto a ser trabalhado pelas partes envolvidas, tendo que ser conquistada através de cordialidades demonstráveis. Sendo assim, através do exercício da confiança são tecidos os relacionamentos, o que também acarreta um processo mútuo de auto revelação.

Compreendemos que expatriados têm suas confianças abaladas quando vivenciam processos de deslocamentos para novos cenários culturais e de informação, acarretando desencaixes das relações sociais, de contextos locais, trazendo a necessidade de reestruturação, buscando uma adaptação que pode ser facilitada pelas escolhas de consumo. Relações de confiança, constância de ambientes e a continuidade da autoidentidade são aspectos que contribuem para a segurança ontológica, o ser no mundo. Para a sua reinserção em novos cenários culturais, seus encaixes serão facilitados (Giddens,1991). Esses reencaixes, segundo Giddens (1991), exigem a reapropriação das relações desencaixadas. 0 reencaixe em novos contextos espaço-temporais é oportunidade para novas relações sociais e trocas de informações.

Segundo Pustrello (2011), o ambiente interfere diretamente na segurança ontológica do sujeito, quando, citando Giddens, fala de constância de ambientes e na confiança gerada na continuidade das relações com pessoas e coisas ao redor. A continuidade nas relações de confiança e a constância de ambientes procuradas pelas pessoas são componentes para sua segurança ontológica num mundo de incertezas e imprevisibilidade e reveladas em suas identidades, geralmente contingentes, sendo tolerantes com a inconsistência ou contradição (Bauman, 2005). Do mesmo modo, Slater (2001) define que as identidades são circunstanciais, quando o sujeito deve escolher, manter, interpretar ou negociar, para que ele possa exibir quem ele quer ser ou parecer. Os recursos materiais e simbólicos presentes nas escolhas de consumo contribuem neste sentido.

Ser um indivíduo ontologicamente seguro para Giddens (2002, p.49) é ter respostas conscientes e práticas para questões existenciais fundamentais que toda vida humana de certa maneira enfrenta. Desde os primeiros dias de vida, tanto a manutenção dos hábitos como as rotinas desempenham um papel importante na elaboração das relações estabelecendo conexões com sentimentos de segurança ontológica no decorrer da vida da pessoa. Giddens (2002) nos diz que essa disciplina nos hábitos e rotinas cria um referencial para sua existência, semeando um sentido de "ser", e o "não-ser", que é um componente da segurança ontológica.

Ao participar das escolhas no modo de vida, realizadas pelo sujeito na definição de seu plano de vida, ele está apoiado em crenças e/ou tradições, harmonizando suas relações de confiança, elaborando suas rotinas e dando continuidade ao seu projeto de vida. Para se sentir ontologicamente seguro, o sujeito também busca nos ambientes uma forma de filtrar ou se adaptar aos riscos e introduzir ou manter relacionamentos que traduzam confiança. A segurança ontológica surge como fonte e papel elaborador das identidades, o sujeito elabora suas identidades partindo de um plano de 
vida escolhido reflexivamente e de fatores que contribuem para segurança ontológica, segundo Giddens (2002).

De acordo com Giddens (2002), os atributos que contribuem para a geração da segurança ontológica são constituídos durante toda a vida do indivíduo, fala das suas convicções, sua história e experiências vividas, seus valores, a confiança construída nessas experiências, o equilíbrio e a base para a construção de uma narrativa pessoal, uma personalização da sua autoidentidade. Atributos como estilos de vida rotinizados, sensação de confiança, tradições, ambientes seguros, crenças, hábitos, conexões significativas, uma narrativa reflexiva, de acordo com o autor estarão relacionados à segurança ontológica do sujeito.

Ao situar o sujeito no contexto das sociedades pré-modernas e modernas, Giddens (1991) nos remete ao ambiente considerado como de segurança, relacionado a diversos fatores de influência. Ele caracteriza o ambiente de confiança e segurança, situando os fenômenos no tempo ao definir que nas sociedades pré-modernas, o ambiente de segurança ontológica é constituído por relações de parentesco, na busca do que é familiar na comunidade local, nas crenças religiosas e na preservação das tradições, como meio de conectar presente e futuro.

No ambiente de segurança, nas sociedades modernas, o autor traz novas características em substituição àquelas da pré-sociedade, como a busca de relações de confiança agora relacionadas a amigos e em relações íntimas, aos sistemas abstratos presentes em suas rotinas, como o uso da internet, o mercado global de estilos e lugares e pelo pensamento orientado para o futuro, como modo de se conectar e estabelecer segurança. Acreditando que ainda podíamos encontrar essas características da pré-sociedade, esses fatores foram analisados como categorias de análise nesta pesquisa.

O quadro teórico-analítico apresentado a seguir traz as categorias analíticas levantadas a partir da perspectiva de segurança ontológica, conforme proposto por Giddens (1991; 2002). Nesse quadro são apresentadas a definição constitutiva, forma como o conceito é apresentado na teoria, e a definição operacional, forma como conceito é observado nas falas dos entrevistados, de cada categoria.

\begin{tabular}{|c|c|c|}
\hline $\begin{array}{l}\text { Categoria } \\
\text { Analítica }\end{array}$ & $\begin{array}{l}\text { Definição Constitutiva } \\
\text { (citação do autor) }\end{array}$ & $\begin{array}{c}\text { Definição Operacional } \\
\text { (como o fenômeno será observado) }\end{array}$ \\
\hline Crenças & $\begin{array}{c}\text { As cosmologias religiosas proporcionam } \\
\text { interpretações morais e práticas da vida } \\
\text { pessoal e social, bem como do mundo } \\
\text { natural, o que representa um ambiente de } \\
\text { segurança para o crente. (Giddens, 1991, } \\
\text { p.93). }\end{array}$ & $\begin{array}{l}\text { Relação entre crença, religião e objetos que } \\
\text { possam ser consumidos. Operacionalizada } \\
\text { pela análise das falas sujeito que } \\
\text { demonstrem que a sua segurança } \\
\text { ontológica foi beneficiada por manutenção } \\
\text { ou busca de crenças religiosas. }\end{array}$ \\
\hline $\begin{array}{l}\text { Narrativa } \\
\text { Identitária }\end{array}$ & $\begin{array}{l}\text { A estória (ou estórias) por meio da qual a } \\
\text { auto identidade é entendida } \\
\text { reflexivamente, tanto pelo sujeito de que } \\
\text { se trata, quanto pelos outros. (Giddens, } \\
\text { 2002, p.222). }\end{array}$ & $\begin{array}{l}\text { Autonomia do sujeito no consumo, } \\
\text { relacionada ao uso de palavras como: } \\
\text { decisão própria, escolher lugares, se } \\
\text { relacionar, confiar, metas, família, o uso da } \\
\text { primeira pessoa para descrever planos, } \\
\text { fazer sentido. }\end{array}$ \\
\hline $\begin{array}{l}\text { Adaptação } \\
\text { Ao Risco }\end{array}$ & $\begin{array}{l}\text { Podemos distinguir o que devo chamar de } \\
\text { engajamento radical, pelo que me refiro a } \\
\text { uma atitude de contestação prática para } \\
\text { com as fontes percebidas de perigo. } \\
\text { Aqueles que assumem uma postura de } \\
\text { engajamento radical alegam que, embora } \\
\text { estejamos cercados por graves problemas, } \\
\text { podemos e devemos nos mobilizar para } \\
\text { reduzir seu impacto ou para transcendê- } \\
\text { los. (Giddens, 1991, p.122). }\end{array}$ & $\begin{array}{l}\text { Consumo e risco. Identificar como o } \\
\text { consumo pode contribuir para a adaptação } \\
\text { aos riscos inerentes aos novos ambientes } \\
\text { de convívio, que tenha trazido segurança. }\end{array}$ \\
\hline $\begin{array}{l}\text { Orientação } \\
\text { Para o }\end{array}$ & $\begin{array}{l}\text { Este é um aspecto fundamental do } \\
\text { 'alongamento' tempo-espaço que as }\end{array}$ & $\begin{array}{l}\text { Entendimento dos sujeitos a respeito de } \\
\text { seus futuros. Foi observado como }\end{array}$ \\
\hline
\end{tabular}




\begin{tabular}{|c|c|c|}
\hline Futuro & $\begin{array}{c}\text { condições da modernidade tornam } \\
\text { possível e necessário. (...) } 0 \text { mapeamento } \\
\text { de futuros } \\
\text { possíveis/desejáveis/disponíveis - se } \\
\text { torna mais importante que mapear o } \\
\text { passado. (Giddens, 1991, p.49) }\end{array}$ & $\begin{array}{l}\text { indivíduos que estão orientados para o } \\
\text { futuro, encontram a segurança ontológica } \\
\text { nos novos ambientes, alimentados pelos } \\
\text { desejos e planejamentos futuros. }\end{array}$ \\
\hline $\begin{array}{l}\text { Relações } \\
\text { de } \\
\text { Confiança }\end{array}$ & $\begin{array}{l}\text { Uma sensação da fidedignidade de } \\
\text { pessoas e coisas, tão central à noção de } \\
\text { confiança, é básica nos sentimentos de } \\
\text { segurança ontológica; daí os dois serem } \\
\text { relacionados psicologicamente de forma } \\
\text { íntima. (Giddens, 1991, p.84). }\end{array}$ & $\begin{array}{c}\text { Relações com pessoas coisas. } \\
\text { Foi observado nas falas dos sujeitos, como } \\
\text { são construídas suas relações com pessoas } \\
\text { e coisas, como são feitas as escolhas e como } \\
\text { estas se relacionam com a segurança } \\
\text { ontológica }\end{array}$ \\
\hline $\begin{array}{l}\text { Mercado } \\
\text { Global de } \\
\text { Estilos e } \\
\text { Lugares }\end{array}$ & $\begin{array}{c}\text { A globalização pode assim ser definida } \\
\text { como a intensificação das relações sociais } \\
\text { em escala mundial, que ligam localidades } \\
\text { distantes de tal maneira que } \\
\text { acontecimentos locais são modelados por } \\
\text { eventos ocorrendo a muitas milhas de } \\
\text { distância e vice-versa. Sentimentos de } \\
\text { ligação íntima ou identificação com } \\
\text { lugares ainda persistem. (Giddens, 1991, } \\
\text { p.60 e p.98) }\end{array}$ & $\begin{array}{c}\text { Oferta e demanda de produtos locais e } \\
\text { globais. Foi observado como a oferta ou } \\
\text { não, de serviços e bens de consumo globais } \\
\text { são utilizadas para manutenção do senso de } \\
\text { continuidade do sujeito e a contribuição } \\
\text { para a segurança ontológica }\end{array}$ \\
\hline Rotina & $\begin{array}{c}\text { A previsibilidade das rotinas } \\
\text { (aparentemente) sem importância da vida } \\
\text { cotidiana está profundamente envolvida } \\
\text { com um sentimento de segurança } \\
\text { psicológica. Quando tais rotinas sofrem } \\
\text { alteração - por quaisquer razões - a } \\
\text { ansiedade transborda, e mesmo aspectos } \\
\text { muito firmemente alicerçados da } \\
\text { personalidade do indivíduo podem ser } \\
\text { afetados e alterados. (Giddens, 1991, } \\
\text { p.89) }\end{array}$ & $\begin{array}{c}\text { Manutenção de rotinas de consumo. Na } \\
\text { análise das entrevistas, observamos como o } \\
\text { sujeito busca manter rotinas na sua vida } \\
\text { cotidiana e os motivos de sua manutenção, } \\
\text { verificando se podem estar ligados a } \\
\text { aspectos relacionados a segurança } \\
\text { psicológica. }\end{array}$ \\
\hline Tradição & $\begin{array}{c}\text { A tradição, em suma, contribui de } \\
\text { maneira básica para a segurança } \\
\text { ontológica na medida em que mantém a } \\
\text { confiança na continuidade do passado, } \\
\text { presente e futuro, e vincula esta confiança } \\
\text { a práticas sociais rotinizadas. (Giddens, } \\
1991, \text { p.95) }\end{array}$ & $\begin{array}{l}\text { Escolha por manutenção de hábitos } \\
\text { significativos fazem parte da construção da } \\
\text { narrativa. Observado em palavras que } \\
\text { demonstrem e expliquem a manutenção de } \\
\text { uma rotina }\end{array}$ \\
\hline
\end{tabular}

Fonte: Elaborado pelos autores

Quadro 1. Quadro Resumo das Categorias Analíticas

Os enfoques teóricos explorados em torno da temática do consumo neste trabalho contribuem para a construção de um conhecimento que investiga o sentido mais amplo do consumo, extrapolando conceitos preestabelecidos sob o viés do consumo somente como atividade de compras, como valor simbólico e cultural, mas como também como uma forma de colaborar na segurança ontológica do sujeito.

\section{PROCEDIMENTOS METODOLÓGICOS}

Com o objetivo de explorar o consumo dos expatriados brasileiros foi adotada a perspectiva da pesquisa qualitativa, de cunho exploratório. Segundo Martins e Bicudo (2005), a característica fundamental da pesquisa qualitativa é o fato de que busca uma compreensão particular daquilo que estuda, já que o foco de sua atenção é dirigido para o específico, o individual, aspirando à compreensão dos fenômenos estudados que somente surgem quando situados. 
Os dados foram coletados com base em entrevistas em profundidade realizadas a distância com nove expatriados brasileiros que vivem ou viveram até pouco tempo atrás em seis diferentes países. A entrevista em profundidade é, essencialmente, uma técnica para estabelecer ou descobrir que existem perspectivas ou pontos de vista sobre os fatos, além daqueles que o entrevistador espera (Arsel, 2018). Assim, o objetivo de investigação é acessar a visão do entrevistado, o que envolve experiências, ideias, valores e estrutura simbólica desse indivíduo. 0 quadro a seguir apresenta resumo dos perfis dos entrevistados. Os nomes dos entrevistados foram preservados e eles são identificados a partir da combinação do local onde vivem ou viveram, o sexo e a idade.

\begin{tabular}{|c|c|}
\hline Entrevistado(a) & Características \\
\hline Inglaterra_gen_f_63 & $\begin{array}{c}\text { Esposa de um militar, acostumada a morar em lugares diferentes, mas } \\
\text { essa é sua primeira experiência internacional. Deixou a casa fechada no } \\
\text { Brasil }\end{array}$ \\
\hline Dubai_gen_m_43 & $\begin{array}{c}\text { Professor universitário, saiu do país em busca de novas experiências em } \\
\text { universidades renomadas, motivado pelo seu plano profissional. Era } \\
\text { solteiro e conheceu uma brasileira que havia ido estudar fora do país, } \\
\text { hoje eles são casados e tem um filho }\end{array}$ \\
\hline $\begin{array}{c}\text { França_Alemanha_ } \\
\text { EUA_gen_f_26 }\end{array}$ & $\begin{array}{c}\text { Decidiu estudar fora do país em busca de nova oportunidade } \\
\text { profissional. Partiu solteira, viveu na França, na Alemanha, se casou, } \\
\text { teve três filhas no exterior e viveu nos EUA antes de retornar ao Brasil } \\
\text { depois de } 18 \text { anos fora }\end{array}$ \\
\hline Inglaterra_gen_24 & $\begin{array}{c}\text { Deixou o país preocupado com sua segurança. Se casou no Brasil e } \\
\text { combinou de ir antes da esposa para arrumar emprego e preparar a } \\
\text { vida do casal fora. Formado em direito no Brasil, tem problemas para se } \\
\text { encaixar nos empregos disponíveis }\end{array}$ \\
\hline Inglaterra_gen_f_34 & $\begin{array}{c}\text { Casada, decidiu deixar o país junto com o marido. O casal vendeu tudo } \\
\text { que possuía, despediu-se dos amigos e familiares e foi viver a } \\
\text { experiência como expatriados }\end{array}$ \\
\hline Canadá_gen_f_45 & $\begin{array}{c}\text { Planejou a saída do país com o marido e as duas filhas ao longo de dois } \\
\text { anos. Tinham condição financeira satisfatória no Brasil, mas planejavam } \\
\text { um futuro com maior segurança e maior conforto }\end{array}$ \\
\hline Dubai_gen_m_36 & $\begin{array}{c}\text { Acompanha esposa transferida pela empresa para fora do país e } \\
\text { conseguiu uma oportunidade na filial da empresa em que trabalha em } \\
\text { Dubai. Se mudaram com uma filha e planejam ter mais uma filha }\end{array}$ \\
\hline Dubai_gen_f_27 & $\begin{array}{l}\text { Foi estudar fora acompanhando e apoiando a mãe. Conheceu o marido } \\
\text { fora, se casou e teve um filho. Depois de morar em outros países e hoje } \\
\text { mora com a família em Dubai }\end{array}$ \\
\hline Inglaterra_gen_m_37 & $\begin{array}{l}\text { Deixou o país apostando numa melhor qualidade de vida e } \\
\text { reconhecimento profissional. Sua irmã já mora há anos na Inglaterra } \\
\text { com marido e filhas e lhe dá apoio }\end{array}$ \\
\hline
\end{tabular}

Fonte: elaborado pelos autores

Quadro 2. Perfis dos Expatriados Entrevistados

As entrevistas aconteceram no período entre julho e novembro de 2019 e inicialmente foram contatadas pessoas de conhecimento dos pesquisadores, que indicaram outros brasileiros expatriados, seguindo a proposta de amostragem bola de neve (Vinuto, 2016). A quantidade de entrevistados foi definida com base no critério de saturação, como proposto por Thiry-Cherques (2009), e quando o acréscimo de informações passou a não alterar a compreensão a respeito das relações entre identidade, consumo e segurança ontológica a coleta de dados foi encerrada. As entrevistas foram realizadas por telefone, com apoio do aplicativo WhatsApp, gravadas e transcritas, com tempo de duração de aproximadamente uma hora cada uma. O uso do aplicativo WhatsApp foi definido por escolha dos entrevistados, visto a impossibilidade de algumas entrevistas serem realizadas via videoconferência, dadas restrições de acesso à internet. As entrevistas tiveram como foco as histórias 
de vida e a reconstrução dos acontecimentos sociais como vividos pelos entrevistados e foram conduzidas de forma a preservar a espontaneidade do entrevistado (Dellagnelo \& Silva, 2005).

Todas as entrevistas seguiram o roteiro construído com base no referencial teórico apresentado na seção anterior e focaram no entendimento dos aspectos comportamentais e emocionais dos sujeitos e na busca pela segurança ontológica, conforme proposto por Giddens (2002) e consolidado no resumo das categorias analíticas (vide Quadro 01). As entrevistas foram transcritas e os arquivos importados para o software MAXQDA 2018, onde foram feitas as codificações dos textos e marcadas as unidades de registro. As entrevistas foram analisadas com base nas categorias analíticas definidas e trechos foram destacados e agrupados na medida em que eram codificados. Com apoio do software, os dados categorizados e agrupados foram consolidados a partir do uso da ferramenta Smart Publisher e, posteriormente, inseridos no corpo do trabalho.

\section{ANÁLISE DAS ENTREVISTAS}

Nesta seção apresentamos as análises das entrevistas. Conforme evidenciamos anteriormente, o foco da investigação foi identificar e descrever os aspectos da segurança ontológica revelados nas experiências dos expatriados e as formas como o consumo se articula no ajustamento das suas identidades. Como forma de orientar a análise, a seção é dividida em sub-seções de acordo as categorias analíticas propostas no Quadro 01. Como forma de auxiliar o acompanhamento da análise incluímos extratos de entrevistas, sendo os entrevistados identificados da forma que indicamos no perfil dos expatriados entrevistados (vide Quadro 02).

\section{Crenças}

Segundo Giddens (1991), algumas crenças pessoais são baseadas em elementos de confiança, o que cria um sentido de segurança ontológica dentro da qual as pessoas criam o seu sistema de crenças pessoal. A crença religiosa oferece esse sentido e o apoio na fé cristã representou um fator decisivo para alguns expatriados e lhes trouxe um lugar de segurança ontológica.

Contudo, identificamos uma outra forma de crença, distinta da religiosa, que foi a crença no país de destino. Essa crença se mostrou mediada pelo consumo, uma vez que os relatos dos expatriados mostram que eles acreditam que a mudança para outro país promove uma vantagem no consumo de bens e serviços, definindo uma nova forma de vida, como apresentado no trecho a seguir:

Meu ponto de apoio está intrinsicamente ligado à minha motivação, porque eu acreditava que aqui no país eu ia ter um consumo mais barato dos produtos em geral, conseguiria comprar supermercado mais barato, carro mais barato, eu acreditava que a segurança aqui seria melhor, que eu ia poder andar na rua despreocupado, que a minha qualidade de vida seria melhor, a questão de saúde, educação para os meus futuros filhos, acreditando no país mesmo.

(Inglaterra_gen_m_24, 2019)

Como vemos, a crença no acesso a bens materiais torna-se uma forma de estabilizar a vida do expatriado. Entendemos que Giddens (1991; 2002) se refere às crenças religiosas como fontes de interpretações morais práticas que geram segurança ao sujeito e percebemos aqui que o consumo é apresentado também como uma forma de interpretação a respeito de princípios de vida estável. Algumas religiões oferecem o bem-estar material como referência a respeito de moralidade e virtude, de forma semelhante o expatriado acredita que a mudança pode trazer acesso a bens que lhe darão estabilidade e conforto o que serve como um referencial de segurança. Nesse caso, a busca pela segurança ontológica está baseada na crença que o país de destino conta com mercado mais desenvolvido e oferece acesso mais fácil a bens e serviços.

\section{Narrativa Identitária}

Segundo Giddens (1991), manter narrativas biográficas passa pelo projeto reflexivo do eu, na manutenção de narrativas coerentes, revisadas, escolhidas, na reconstituição da vida diária num estilo de vida, num planejamento de vida reflexivamente organizado. 
A identidade cultural, caracterizada em algumas narrativas, fala dos hábitos de consumo e, nesse ponto observamos duas trajetórias identitárias dos expatriados: uma que está relacionada à busca por adaptação e incorporação dos novos hábitos; e outra ligada à conservação dos hábitos do país de origem. Essas duas trajetórias são usadas pelos expatriados, por vezes de forma intercalada, como forma de regulação de sua identidade frente a si e aos outros e obtenção da segurança ontológica.

As falas dos entrevistados apontaram que o consumo de alimentos pode colaborar para essa regulação identitária. Os hábitos alimentares são imersos em dimensões simbólicas e culturais do indivíduo (Yamagata \& Sauerbronn, 2019) e o consumo de alimentos apareceu nas falas dos entrevistados como forma de busca pela segurança ontológica do expatriado. No trecho apresentado a seguir, vemos que o expatriado buscou formas de adaptar seu consumo à sua identidade cultural e à cultura do país destino, fazendo do consumo um facilitador de sua adaptação em busca de maior segurança ontológica.

Tem frutas que eu fiquei 17 anos sem comer, cheguei a comprar uma fruta semelhante, mas que não tinha o mesmo sabor. Então, me causava uma certa melancolia por não encontrar aquele sabor e quando eu encontrava alguma fruta, mesmo vindo da África, mas que me trazia aquele saborzinho da fruta daqui do Brasil, isso me fazia me alegrar muito. Mas eu também abri bastante a minha mente pra gostar e apreciar e viver os prazeres das estações lá, no caso, na França e não é difícil se apaixonar pela cultura francesa, porque ela tem muitos encantos.

(França_Alemanha_EUA_gen_f_26, 2019)

Segundo Giddens (1991), o local e o global se tornaram entrelaçados. Podemos verificar que a conexão com a comunidade brasileira no país de destino é uma forma de facilitar a adaptação e orientação do consumo, em direção à segurança ontológica. 0 consumo de produtos brasileiros e a estabilidade identitária com a comunidade do país de origem se apresentou como uma forma de alcançar a segurança ontológica. Assim, em alguns casos, por mais que o expatriado tivesse acesso a consumo diferenciado do país de destino, o consumo do produto brasileiro serve como forma de se aproximar simbolicamente de uma narrativa identitária segura, como no relato abaixo.

Então, você vai no Apple Music, baixa o seu pagode, né? Como eu sou do Rio, baixo alguns funks, enfim, uma MPB. Eu já coloco no carro, porque estou de saco cheio de música internacional, isso é uma questão de consumo.

(Dubai_gen_m_36, 2019)

Em outros momentos, os expatriados mostram mais claramente a necessidade de também serem aceitos nos países de destino e, dessa forma, o consumo se torna uma forma de alinhamento aos hábitos locais. Vemos a importância do consumo como uma forma de buscar aceitação em relatos onde o consumo atuou como uma forma de responder às inseguranças e de buscar aprovação da sua identidade, como uma característica adaptável a partir das suas escolhas. A busca pela autonomia do sujeito foi revelada em vários momentos, como quando o expatriado mostra que sua decisão de deixar o Brasil é apoiada pela confiança através do consumo, ou seja, das possibilidades de consumo disponíveis no país de destino de sua expatriação.

Acho que aumenta a confiança, aquela impressão que você toma a decisão certa. Do que o país aqui te oferece de novo, mais a questão de consumo. De você poder pagar um colégio ótimo para tua filha, que não poderia no Brasil, você ter segurança, que você não paga, é um direito do cidadão. De novo a questão de cultura, a questão de casa, enfim, isso tudo. Tudo que eu vivo aqui me dá mais confiança que eu tomei a decisão certa. Me dá mais gás, empolgação para continuar aqui, eu estou vendo as coisas que são boas.

(Dubai_gen_m_36, 2019)

O consumo é apresentado como uma referência, um ponto de apoio para expatriados construírem suas identidades a partir do consumo alinhado às escolhas de locais, focando em maior 
segurança. Neste sentido, o consumo suporta as histórias por meio das quais o expatriado constrói a sua narrativa identitária para si e para os outros e alcança autonomia.

\section{Adaptação ao Risco}

Segundo Giddens (2002), reconhecer a existência de um risco ou conjunto de riscos é aceitar não só a possibilidade de que as coisas possam sair erradas, mas que esta possibilidade não pode ser eliminada. 0 enfrentamento foi uma forma encontrada para lidar com as inseguranças, em alguns casos, lidando com a dor, com suas emoções e como risco de não conseguir se expressar na língua do país anfitrião, quando por exemplo uma expatriada relatou a sua ida a um dentista no Canadá e todas as suas inseguranças reveladas nesta experiência.

Os riscos que surgiram nos relatos dos expatriados também demonstraram características inerentes à expatriação, como por exemplo a preocupação com o expatriado em relação a sua saúde e os aspectos relacionados em ser um estrangeiro, o que colaborou para sua insegurança ontológica, podendo ser remediado com o consumo de serviços de cuidado do corpo, porém adaptados a uma nova rotina no país. Nesse sentido, as relações de confiança com membros da comunidade brasileira permitem que o consumo reduza alguns riscos envolvidos na mudança.

Dificuldade no início foi a alimentação. A falta do feijão, do café, essas coisas, né, que a gente gosta aqui e lá a gente não tem, não dispõe. Mais na parte de alimentação, mesmo. E quando ia alguém daqui a gente pedia: 'Ah, traz feijão! Traz café! Essas coisas a gente pedia mesmo.

(Londres_gen_f_63, 2019)

Há uma diferença entre café da manhã brasileiro e café da manhã britânico. Esse é um hábito que eu meio que transportei pra cá, porque o café da manhã britânico, o english breakfast, que eles chamam, que é ovo, bacon, tomate, cogumelo, enfim, bastante coisa, não é uma coisa muito saudável e muito normal pra gente. Então, eu continuo comprando pão e comendo o pão com presunto, o normal do brasileiro. 0 café da manhã é uma coisa que realmente eu transportei.

(Inglaterra_gen_m_24, 2019)

Giddens (1991) aponta que, embora o indivíduo possa estar cercado por dificuldades, ele pode e deve mobilizar recursos para reduzir o impacto dessas adversidades. Os trechos de entrevistas apresentados mostram que o expatriado adapta algumas das opções de consumo locais àquela original, que lhe dá mais conforto e diminui seus riscos. 0 expatriado utiliza o consumo como maneira de se relacionar com a nova condição de vida e forma racional consciente de adaptação ao risco.

\section{Orientação para o futuro}

0 processo de adaptação se efetua continuamente durante a experiência da expatriação. 0 expatriado passa por uma fase inicial considerada mais difícil, na qual todas as suas necessidades físicas, financeiras, psicoemocionais e de consumo, bem como suas indecisões, inseguranças e impulsos estão à sua frente. Todo esse processo é facilitado quando o foco do expatriado não está somente no presente, mas em processar seu plano também para o futuro. Vimos isso sendo relatado em alguns casos em que os entrevistados, apesar de viverem experiências de uma expatriação recente, usaram o planejamento do consumo futuro para administrar a insegurança.

Muitas das vezes, a gente passa por situações de privação em função de alguma coisa que a gente planeja consumir lá na frente. Por exemplo, a gente não tem casa própria ainda, então, a gente está juntando dinheiro para dar entrada numa casa própria, para conseguir manter uma casa. Isso tudo faz com que a gente não esbanje dinheiro indo a cinema toda hora, jantando fora todo dia, viajando. Então, com certeza, a gente passa por privações.

(Canada_gen_f_45, 2019) 
O consumo serve como suporte para o planejamento de vida do expatriado, como uma orientação para sua estabilização e, portanto, segurança ontológica. 0 consumo oferece concretude a algo que é ainda imaterial ao expatriado, que é seu futuro da vida em um novo lugar. Quando o expatriado consegue planejar o seu consumo e entender que as privações de consumo no momento presente o levariam a alcançar o consumo planejado, percebe uma forma de gerar segurança para si.

Hoje a minha vida é mais planejada. Aqui eu entendi que é um passo de cada vez. Como eu falei, não dá para parcelar compras, então, você não pode ficar acumulando dívidas, porque isso vai te atrapalhar lá na frente. Mas o nosso plano é comprar nossa casa própria, comprar casa nova, porque aqui tem muitas construtoras que compram terrenos, derrubam várias casas e montam casas novas, casas eficientes, casas mais modernas. Aí, você consegue fazer um financiamento.

(Inglaterra_gen_m_37, 2019)

Como apresentado por Giddens (1991), sujeitos orientados para o futuro encontram a segurança ontológica nos novos ambientes, novos países de moradia, mapeando os futuros possíveis e deixando o passado em posição de menor importância. Nesse sentido, a orientação para o futuro ganha maior previsibilidade e alguma concretude em projetos de consumo de maior porte.

\section{Relações de Confiança}

A falta de convivência com amigos e parentes que ficaram no Brasil foi apontada por expatriados como algo que precisava ser resolvido de alguma forma. Assim, mesmo considerando o significado dado à família e aos amigos brasileiros, a necessidade de se relacionar pessoalmente, vivenciando e compartilhando experiências, move o expatriado para novas relações e o consumo também media esses encontros de forma a colaborar para segurança ontológica. 0 convívio com a comunidade brasileira e o consumo cultural do seu país de origem foi visto como um fator que contribuiu para a segurança ontológica, substituindo a falta de convívio de familiares e amigos do Brasil e suportando maior equilíbrio emocional, como no trecho a seguir:

Os meus amigos no Brasil, eles estão no Brasil, e a gente como ser humano, a gente precisa do contato físico, olhar no olho, estar perto, estar junto. Eu não tenho como ir ao cinema com um amigo que está no Brasil, eu estando no Canadá. Então a gente precisa deste relacionamento vivo e a gente foi abençoado com relacionamentos assim igualmente especiais aqui.

(Canada_gen_f_45, 2019)

As relações de confiança, nas condições sociais contemporâneas, saem do âmbito familiar e são compensadas por laços pessoais construídos em substituição. Como apresentado por Giddens (1991), a noção de confiança está relacionada a uma relação genuína com pessoas e coisas e é básica nos sentimentos de segurança ontológica. Nesse sentido, as coisas e os seus significados são revistos ou reforçados e o sujeito encontra formas de confiança através do consumo.

Eu acho que hoje definitivamente, a Inglaterra é como estar no Brasil. Eu tenho a mesma segurança, a mesma sensação, a mesma satisfação. Eu não me sinto mais tanto uma estrangeira fora do ninho. Eu acho que eu conquistei meu espaço, eu consegui me acomodar. Eu consegui entrar numa rotina, ter as minhas coisas, tanto materiais quanto pessoais, atingir os meus targets, ter os meus amigos. Então, hoje eu sinto como uma continuidade. Pra mim eu não vejo mais essa quebra entre Brasil e Inglaterra. Pra mim aqui é uma continuidade da minha vida [...] eu me sinto completamente confortável na vida que eu tenho, como se estivesse no Brasil.

(Inglaterra_gen_f_34, 2019)

\section{Mercado Global de Estilos e Lugares}

Para Giddens (1991), a globalização intensifica as relações sociais em escala mundial e conecta localidades distantes de forma que os acontecimentos locais e globais são cada vez mais relacionados. Quando a cultura global e local se misturam, o acesso a uma cultura global passa tanto pela 
manutenção da cultura de origem quanto pela absorção da cultura do país de destino. A questão da adaptação à língua estrangeira, em muitos relatos de expatriados revelou o quanto o não domínio ou a não intimidade com a língua foi um fator de insegurança, o que poderia ter comprometido a sua experiência como expatriado. Foram analisados dentro desta categoria, questões que se destacaram nos relatos dos expatriados, relacionados a adaptação a língua estrangeira e ao acesso a um consumo diferenciado.

A barreira encontrada no domínio da língua estrangeira comprometeu a liberdade de relacionamento de alguns expatriados entrevistados. 0 bloqueio gerado por não dominarem a língua do país trouxe características que comprometeram as suas identidades e a segurança ontológica. Podemos verificar que um expatriado com pouco tempo de expatriação, apesar de enxergar o consumo como uma válvula de descompressão para sua adaptação, esbarrou com a dificuldade de se expressar na língua do país, trazendo componentes novos para a sua adaptação ao país. 0 não domínio da língua estrangeira foi um limitador nas características da personalidade, na capacidade de se relacionar, desenhando um comportamento diferenciado, de acordo com relatos.

A experiência que eu tive na Alemanha, foi totalmente diferente. Um país que eu cheguei e não sabia falar o idioma local, não sabia ler os rótulos, não tinha conhecimento nenhum de marca, do que assistir. Enfim, o acesso era muito mais difícil para consumir os produtos e demais serviços.

(Dubai_gen_f_27, 2019)

0 acesso a um consumo diferenciado, define o expatriado que usou o consumo do mercado global como um artifício encontrado para colaborar na sua segurança ontológica, pela facilidade de acesso a produtos globais e pela qualidade dos produtos oferecidos. 0 acesso aos diferentes fluxos culturais permeia uma identidade traduzida pela adaptação, o que pode ocorrer em níveis diferentes e caracterizar um consumo diferenciado por absorção da nova cultura.

Você começa a ver o que pode ser substituído, o que pode substituir o pão de queijo, o queijo minas, o salame de porco, a mortadela. 0 presunto que a gente comia não é igual aqui, né? A mortadela é de frango. A salsicha do cachorro-quente não é de porco, é de frango. Você acaba se acostumando. Demora um pouquinho, mas você deixa de comparar ao Brasil. Se você ficar comparando toda hora, você acaba ficando chateado.

(Dubai_gen_m_36, 2019)

A adaptação ao consumo global trouxe características de uma identidade mais global, mais adaptada, como no relato a seguir:

O legal é que com o tempo você acaba substituindo. Por exemplo, você quer fazer um escondidinho. Aí, você precisa de um inhame, você não tem um inhame do Brasil, mas você tem o da Índia. Você quer comer uma manga, então, como você não tem a manga do Brasil, você tem a manga da Austrália. Você vai tentando adaptar seu paladar também ao que está disponível no momento.

(Dubai_gen_f_27, 2019)

0 acesso ao consumo diferenciado associado as facilidades encontradas em outro país e o relato da qualidade oferecida superior aos produtos brasileiros, também colaboraram para a segurança ontológica. De qualquer forma, a conexão entre o que está disponível nos mercados dos países de destino com o que consumia no Brasil mostra que o mercado global serve como base para se entender uma possibilidade de o consumo servir ao expatriado como forma de alcançar a segurança ontológica.

\section{Rotina}

Os hábitos de consumo revelam uma preferência, uma constância que traz sentido, da segurança às novas formas de vida, às novas narrativas, reforçando identidades, amenizando ansiedades e inseguranças trazidas por tudo que é novo, ao lugar novo, aos costumes do lugar. 
Segundo Giddens (1991), a segurança ontológica e a rotina estão intimamente vinculadas através da influência difusa do hábito.

A disponibilidade de amplo sortimento de produtos no mercado do local de destino foi entendida como fonte de conforto, uma vez que a rotina é pouco afetada quando é possível replicar aquela que o expatriado vivia no país de origem. 0 consumo, portanto, é uma garantia da rotina e uma eventual dificuldade em conseguir consumir um produto seria uma manifestação que abalaria a segurança ontológica do expatriado.

O que muitas vezes eu faço é substituir um produto que eu consumia no Brasil por um produto que tem uma similaridade local. Dou um exemplo do requeijão. Requeijão é um produto que teoricamente só existe no Brasil, mas tem um queijo pasteurizado árabe que é muito próximo ao requeijão.

(Dubai_gen_m_43, 2019)

Nesse ponto, os hábitos de consumo colaboraram para trazer sentido, como a escolha das rotinas e a sua repetição geraram um lugar seguro e experiências muito pessoais, como no relato abaixo. A tecnologia também permite que a rotina seja menos afetada e o expatriado se sinta mais seguro, mesmo que distante de parentes e amigos.

Eu acho que eu perdi bastante na questão do futebol. Eu sou viciado em futebol, mas, enfim, eu consigo acompanhar aqui porque tem uma caixinha tipo Apple TV que tem todos os canais do Brasil, que passa ao vivo, então eu acompanho as partidas de futebol.

(Dubai_gen_m_36, 2019)

(...) mas tem coisas que eu sinto falta, como o Jornal Nacional. Eu e o meu marido, a gente tenta ainda assistir ao fantástico toda semana, talvez um jogo de futebol, que você gostaria de assistir, que você sente saudade daquela rotina de estar com teu núcleo de família e você não tem mais tanto acesso com facilidade.

(Dubai_gen_f_27, 2019)

Sendo o desencaixe uma manifestação da insegurança ontológica, o consumo de referência foi a forma encontrada para colaborar numa melhor adaptação e na segurança ontológica, conforme o relato a seguir:

Como era fronteira com a França, eu ia fazer compras na França. Eu pegava o carro e ia para o lado francês fazer compras porque eu não encontrava prazer algum nos supermercados alemães. Então, pra mim, foi um choque.

(França_Alemanha_EUA_gen_f_26, 2019)

Quando a rotina é quebrada ou não pode ser seguida ocorre um desencaixe, associado às situações em que o expatriado não teve as suas necessidades de consumo atendidas devido ao deslocamento geográfico e à falta de opções para o consumo. 0 desencaixe é ocasionado pela alteração no referencial de segurança ontológica do sujeito nas práticas da vida diária. Nesses momentos é necessária uma reestruturação e o expatriado pode não ter total confiança no novo projeto de vida, o que provoca estranhamento e amplia a dificuldade de adaptação ao local e/ou às novas rotinas e formas de consumir.

\section{Tradição}

A última categoria analisada é a categoria de tradição, que se refere aos hábitos mais contínuos do sujeito e está relacionada à experiências vivenciadas em família ou com pessoas com laços fortes. Conforme proposto por Giddens (1991), a tradição contribui para a manutenção da segurança ontológica, fazendo o vínculo entre passado, presente e futuro. Nesse sentido, observamos que os expatriados lidam com a tradição através do consumo, seja utilizando-os como referência 
ausente, seja adaptando essa ausência de produtos. No relato a seguir observamos uma forma de negociação entre referência tradicional, a marca do supermercado reconhecida pelo expatriado, e a ausência do produto tradicional, que lhe traria segurança ao viver afastado de seu país de origem.

Tem Carrefour aqui, então, você pensa: que bom! Tem Carrefour no Brasil também, você vai no mercado, não tem farofa, vai no mercado não tem guaraná antártica, não tem queijo minas, não tem pão de queijo, para achar aquela picanha para o churrasco é difícil sabe.

(Dubai_gen_m_36, 2019)

O consumo acaba sendo para o expatriado uma forma concreta e, ao mesmo tempo, flexível de conexão com a tradição que gera segurança ao sujeito. 0 resgate do consumo realizado no Brasil pode ser percebido como uma busca por segurança. No entanto, por vezes essa busca é frustrada e são necessárias adaptações do consumo. Como vemos no trecho a seguir, a referência tradicional, a feijoada, é adaptada a partir do uso de ingredientes disponíveis no país de destino. Há uma negociação entre os objetivos de consumo tradicionais e o que o expatriado consegue acessar através do consumo.

Acabei adaptando o feijão, algumas carnes secas e fazendo uma feijoada a minha maneira na Alemanha, tentei fazer churrasco tanto na França quanto na Alemanha, tive muita dificuldade porque o corte bovino é totalmente diferente, então você nunca vai encontrar uma peça igual, cortada de maneira igual.

(França_Alemanha_EUA_gen_f_26, 2019)

0 expatriado procura através do consumo encontrar um lugar de segurança. 0 resgate das formas de consumo de seu país de origem, mesmo que alvo de adaptações, serve como uma fonte de tradições que pode ser acessada no mercado. A segurança ontológica está associada à tradição e o expatriado busca conexões com sua origem em produtos como forma de entendimento de si no mundo a partir de coisas.

\section{CONCLUSÃO}

Essa pesquisa teve o propósito de analisar como o consumo colabora no ajustamento das identidades do expatriado e que aspectos de segurança ontológica foram revelados em suas experiências vividas fora do país. Os relatos dos expatriados mostraram como o consumo é utilizado como mecanismo de gestão da segurança ontológica do sujeito, oferecendo tanto conexões com o país de origem, quanto com o país de destino. 0 consumo serve como suporte para novos projetos de vida e fonte de motivação para o expatriado frente às inseguranças surgidas.

Vimos que a crença no acesso a bens no país de destino é um componente importante na geração de segurança ontológica ao expatriado e que o consumo oferece bases para a narrativa identitária do sujeito fora de seu país de origem, permitindo que ele se sinta estável. Nesse sentido ainda, os expatriados apontaram que utilizam o consumo como forma de negociar consigo mesmos suas novas condições de vida no país de destino e facilitar a adaptação aos riscos da mudança. Essa posição é reforçada pelo mercado globalizado que tornam disponíveis aos expatriados sortimentos de produtos do país de origem e de outras partes do mundo. Dessa forma, as rotinas são de alguma forma mantidas e o expatriado experimenta menos a sensação de desencaixe associada à falta de um referencial de segurança ontológica. A orientação para um futuro mais previsível ganha materialidade através das opções de consumo percebidas pelos expatriados e serve igualmente como apoio para os sujeitos.

No tocante às contribuições acadêmicas este trabalho avança no entendimento do consumo como fonte de estabilidade do sujeito, explorando o caminho iniciado por Gouveia e Ayrosa (2020). Esse trajeto aponta para dimensões subjetivas do consumo que se diferenciam das propostas usuais de entendimento sociocultural do consumo propostas em trabalhos de CCT e o presente trabalho se alinha a uma proposta mais reflexiva para os estudos de consumo. A aproximação ao referencial teórico da segurança ontológica é conectada ao universo social e cultural do sujeito, mas está ancorada em na sua subjetividade, tópico considerado relevante há muito tempo, mas pouco explorado no campo dos estudos de consumo. 
Esperamos que o presente trabalho possa servir para incentivar outros pesquisadores a ampliarem a compreensão a respeito de questões relacionadas à segurança ontológica e ao consumo. Durante a coleta de dados no campo surgiram informações que não faziam parte do escopo desta pesquisa, mas que acreditamos ser relevantes para serem tratadas em pesquisas futuras. Neste estudo não foram exploradas as representações do consumo no país de origem dos expatriados. Considerando os resultados alcançados poderemos retornar aos expatriados em pesquisas futuras e construir um entendimento mais profundo a respeito de suas experiências de consumo originais. 0 retorno ao consumo anterior à experiência de expatriação pode servir como plataforma para ampliação da dimensão reflexiva do consumo explorada no presente trabalho. 0 suporte metodológico também pode ser reforçado com propostas de coleta e análise de dados mais reflexivas que poderiam ser desenvolvidas em paralelo a essa exploração. Ainda são necessários muitos passos para que ampliemos a compreensão a respeito da subjetividade do sujeito no consumo.

\section{References}

Adams, B. G., \& Van de Vijver, F. J. R. (2015). The many faces of expatriate identity. International Journal of Intercultural Relations, 49, 322-331.

Arnould, E. J., \& Thompson, C. J. (2005). Consumer Culture Theory (CCT): Twenty Years of Research. Journal of Consumer Research, 31(4), 868-882.

Arsel, Z. (2018). Fazendo perguntas com um foco reflexivo: um guia para o planejamento e condução de entrevistas. Revista Interdisciplinar de Marketing, 8(2), 84-98.

Barbosa, L. (2004). Sociedade de consumo. ZAHAR. ISBN 9788571108134 Disponível em $<$ https://books.google.com.br/books?id=qPn PcnZR88C>. acesso em 05/07/18.

Bauman, Z. (2005). Entrevista a Benedetto Vecchi. Rio de Janeiro: ZAHAR. ISBN 9788537807736 Disponível em < https://books.google.com.br/books?id=qOov0K59CtgC > acesso em 04/05/18

Belk, R. W. (1988). Possessions and the extended self. Journal of Consumer Research, 15(2), 139-168.

Bicudo, M. A. V. (2005). Fenomenologia: Confrontos e Avanços. Cortez. ISBN 9788524907586. Disponível em < https://books.google.com.br/books?id=71jEAAAACAAJ> acesso em 18/08/18

Borges, J. V., Campos, A. C., Cappelle, M. C. A., \& Rezende, D. C. de. (2020). Identidade e Consumo na Meia-idade: Uma Perspectiva Teórica. Revista Interdisciplinar de Marketing, 10(1), 62-75.

Bundy, L. (2017). Expatriates go shopping: food and shopping acculturation. International Journal of Retail \& Distribution Management, 45(10), 1079-1094.

Campbell, C. (2006). Eu compro, logo sei que existo. As bases metafísicas do consumo moderno. In L. Barbosa, \& C. Campbell, (Orgs.). Cultura, consumo e identidade. Rio de Janeiro: FGV.

Canclini, N. G. (1999). Consumidores e Cidadãos: conflitos multiculturais da globalização. Rio de Janeiro: Ed. UFRJ. ISBN 9788585781019. Disponível em: https://books.google.com.br/books?id=5o1VAAAAMAAJ. acesso em 04/06/18

Carvalho, S. W., Luna, D., \& Goldsmith, E. (2019). The role of national identity in consumption: An integrative framework. Journal of Business Research, 103, 310-318.

Cupolillo, F. B. N., \& Ayrosa, E. A. T. (2016). Reflexões Sobre Consumo, Identidade e Masculinidade em Um Bairro Carioca. Revista Interdisciplinar de Marketing, 5(2), 19-33. https://doi.org/10.4025/rimar.v5i2.26435

Dellagnelo, E. H. L., \& Silva, R. C. (2005). Análise de conteúdo e sua aplicação em pesquisa na administração. In: VIEIRA, M. M. F.; ZOUAIN, D. M. (Orgs.). Pesquisa Qualitativa em Administração: Teoria e Prática (pp. 97-118). Rio de Janeiro: FGV.

Ferreira, A. B. H. (1993). Novo Dicionário Aurélio da Língua Portuguesa (2a ed.) Rio de Janeiro: Nova Fronteira.

Giddens, A. (1991). As Consequências da Modernidade. São Paulo: UNESP. ISBN 85.7139.022.5.

Giddens, A. (2002). Modernidade e Identidade. Rio de Janeiro: ZAHAR. ISBN 85.3780.878.8.

Giddens, A. (2009). A Constituição da Sociedade. WMF Martins Fontes, 3aㅡ edição. ISBN 85.7827.068.1. 
Gouveia, T. M. O. A. \& Ayrosa, E. A. T. (2020). Identity, consumption and ontological security: trying to live on the edge of the aesthetic norm. Revista Organizações \& Sociedade, 27(92), 132-151.

Hall, S. (2006). A Identidade Cultural na Pós-Modernidade. Rio de Janeiro: DP\&A. ISBN 9788574904023. Disponível em: < https://books.google.com.br/books?id=4TcuzSIYB9cC >. acesso em 15/04/19.

Hu, J. \& Duval, Y. (2003). Qualitative analysis and implications of Chinese expatriates' food consumption behavior. Journal of Food Products Marketing, 9(1), 31-47.

McCracken, G. (2003). Cultura e Consumo: novas abordagens ao caráter simbólico dos bens e das atividades de consumo. Tradução Fernanda Eugênio. Rio de Janeiro. Mauad.

Ministério das Relações Exteriores. (2016). V Conferência Brasileiros no Mundo. Disponível em <http://www.funag.gov.br/index.php/pt-br/2015-02-12-19-38-42/928-v-conferenciabrasileiros-no-mundo $>$. acesso em 10/05/18.

Rocha, E. (1995). Magia e Capitalismo: um estudo antropológico da publicidade. São Paulo: Brasiliense.

Rocha, E. (2006). Representações do consumo. Estudos sobre a narrativa publicitária. Rio de Janeiro: PUC-RJ.

Schau, H. J., Gilly, M. C., \& Wolfinbarger, M. (2009). Consumer identity renaissance: the resurgence of identity-inspired consumption in retirement, Journal of Consumer Research, 36(2), 255-276.

Slater, D. (2001). Cultura do Consumo \& Modernidade. São Paulo: Nobel.

Thiry-Cherques, H. R. (2009). Saturação em pesquisa qualitativa: estimativa empírica de dimensionamento. Revista PMKT, 3, 20-27.

Thompson, C. J., \& Tambyah, S. K. (1999). Trying to Be Cosmopolitan. Journal of Consumer Research, 26, n. dezembro, p. 214-241. Disponível em: < https://www.researchgate.net/profile/Craig_Thompson3/publication/24099030_Trying_to_Be_C osmopolitan/links/53dfbf830cf2a768e49bcedc/Trying-to-Be-Cosmopolitan.pdf> acesso em $11 / 04 / 2019$

Thompson, S. A., \& Loveland, J. M. (2015). Integrating identity and consumption: an identity investment theory. Journal of Marketing Theory and Practice, 23(3), 235-253.

Usunier, J. C. (1999). Food consumption and the expatriation experience: a study of american expatriates in France, in E - European Advances in Consumer Research Volume 4, eds. Bernard Dubois, Tina M. Lowrey, and L. J. Shrum, Marc Vanhuele, Provo, UT: Association for Consumer Research, Pages: 352-360.

Vinuto, J. (2016). A Amostragem em Bola de Neve na Pesquisa Qualitativa. Disponível em <https://www.semanticscholar.org/paper/A-AMOSTRAGEM-EM-BOLA-DE-NEVE-NA-PESQUISAUM-DEBATE- Vinuto/cd8e3 ecb215bf9ea6468624149a343f8a1fa8456>acesso em 04.02.20.

Yamagata, F. C., \& Sauerbronn, J. F. R. (2019). Alimento e comida: Reflexões sobre história do alimento, consumo e significados. Diálogos com a Economia Criativa, 4(10), 7-19. 